\title{
Application of Activity-Based Costing in a Manufacturing Company: A Comparison with Traditional Costing
}

\author{
Gonca Tuncel, Derya Eren Akyol, Gunhan Mirac Bayhan, and Utku Koker \\ Department of Industrial Engineering, University of Dokuz Eylul, \\ 35100 Bornova-Izmir, Turkey \\ \{gonca.tuncel, derya.eren, mirac.bayhan\}@deu.edu.tr
}

\begin{abstract}
Activity-Based Costing (ABC) represents an alternative paradigm to traditional cost accounting system and has received extensive attention during the past decade. Rather than distorting the cost information by using traditional overhead allocation methods, it traces the cost via activities performed on the cost objects (production or service activities) giving more accurate and traceable cost information. In this paper, the implementation of $\mathrm{ABC}$ in a manufacturing system is presented, and a comparison with the traditional cost based system in terms of the effects on the product costs is carried out to highlight the difference between two costing methodologies. The results of the application reveal the weak points of traditional costing methods and an S-Curve which exposes the undercosted and overcosted products is used to improve the product pricing policy of the firm.
\end{abstract}

\section{Introduction}

The customer driven environment of today's manufacturing systems and the competitive pressure of the global economy force manufacturing services and organizations to become more flexible, integrated and highly automated in order to increase their productivity at reduced costs. But it is impossible to sustain competitiveness without an accurate cost calculation mechanism [1]. Proposed by [2], as an alternative method to traditional cost accounting methods, ABC assigns costs to activities using multiple cost drivers, then allocates costs to products based on each product's use of these activities [3], [4]. Using multiple activities as cost drivers, it reduces the risk of distortion and provides accurate cost information [3].

In an $\mathrm{ABC}$ system, the total cost of a product equals the cost of the raw materials plus the sum of the cost of all value adding activities to produce it [4]. In other words, the ABC method models the usage of the organization resources by the activities performed and links the cost of these activities to outputs, such as products, customers, and services [5]. Each product requires a number of activities such as design, engineering, purchasing, production and quality control. Each activity consumes resources of different categories such as 
the working time of the manager. Cost drivers are often measures of the activities performed such as number of units produced, labor hours, hours of equipment time, number of orders received.

In traditional cost accounting systems, direct materials and labor are the only costs that can be traced directly to the product. By using the ABC system, activities can be classified as value-added and non-value-added activities. In order to improve the performance of the system, non-value-added can be eliminated.

Despite the advantages of providing accurate costs, it requires additional effort and expense in obtaining the information needed for the analysis [6]. However, a proper design tool can help to reduce time used for modeling and overcome the difficulties present in designing a cost model.

The primary objective of this paper is to develop an $\mathrm{ABC}$ system for a sanitary-ware company and to compare the results of ABC with traditional costing methods. In other words, the aim of $\mathrm{ABC}$ analysis is to guide improvement efforts of management in the right direction by providing accurate information about activities.

The organization of the paper is as follows: In section 2, the methodology of $\mathrm{ABC}$ is explained. A case study is presented in section 3 to illustrate the application of ABC in a company. Finally, in section 4, the conclusions and the future research directions are given. Some suggestions are offered to improve the performance of the company.

\section{Activity-Based Costing (ABC)}

$\mathrm{ABC}$ is an economic model that identifies the cost pools or activity centers in an organization and assigns costs to cost drivers based on the number of each activity used. Since the cost drivers are related to the activities, they occur on several levels:

1. Unit level drivers which assume the increase of the inputs for every unit that is being produced.

2. Batch level drivers which assume the variation of the inputs for every batch that is being produced.

3. Product level drivers which assume the necessity of the inputs to support the production of each different type of product.

4. Facility level drivers are the drivers which are related to the facility's manufacturing process. Users of the ABC system will need to identify the activities which generate cost and then match the activities to the level bases used to assign costs to the products.

While using the ABC system, the activities which generate cost must be determined and then should be matched to the level drivers used to assign costs to the products.

The implementation of the ABC system has the following steps:

1. Identifying the activities such as engineering, machining, inspectionetc.

2. Determining the activity costs 
3. Determining the cost drivers such as machining hours, number of setups and engineering hours.

4. Collecting the activity data

5. Computing the product cost

\section{Implementation of the ABC Method: A Case Study}

The implementation study presented here took place in one of the leading sanitaryware companies in Turkey [7]. It has a production capacity of 6.8 thousand tons. Like many sanitaryware manufacturers, the company includes some common processes. First stage of the processes is done in the bulk-preparement department which is in charge of preparing the essential quantities of bulk bearing. Recipes are prepared for each production run and according to these ingredient recipes, the bulks are prepared by the electronically controlled tanks. After the bulk is ready, it can be sent to two different departments, pressured and classical casting departments.

In pressured casting department, the bulk is given shape by the pressured casting process. The process uses automated machines and has shorter cycle times when compared to classical casting department. However, the bulk used in this department must have the characteristics of strength and endurance. The output of this department is sent to glazing department.

Classical casting is the second alternative to produce sanitaryware products. In this department, most of the operations are performed by direct labor. The cycle times of the products are longer than the pressured casting department. The output of this department is "shaped and casted" bulk and sent to the glazing department, too.

In glazing department, shaped bulk is glazed. This stage can be defined as polishing the products with a protective material from external effects. The output of this department is sent to tunnel oven.

In tunnel oven, the products are heated over 1200 degrees Celsius. After staying in theses ovens for a period of time, the products are inspected by the workers. However, some of the output may have some undesired characteristics like the scratches, etc. In this case, these products are sent to the second heat treatment where they are reworked and heated again. The proper output is sent to packaging while the defected ones are sent to waste.

Finally, in packaging department, products are packaged and shrunken.

Company has been using a process costing logic for obtaining the proper costing of its products. Process costing is also a widely used costing tool for many companies. This method recognizes the following cost pools:

- Direct Labor: All workers taking place in the production are recognized as direct labor and this pool is the most common pool used in every stage.

- LPG-Electricity hot water: These items are important costing element in casting departments.

- Packaging: This cost is observed in the final stage of the firm called final packaging. It includes packaging and shrinking of the products. 
- Overheads: This is also common cost pool for all the stages in the firm. It includes depreciation, rents, indirect labor, materials, and miscellaneous costs.

In order to perform ABC calculations, process costing sheets are used. Because process costing aggregates the cost in the case of more than one product, it is difficult to obtain the correct results. The correct results with process costing can only be achieved when there is a single homogenous product. After analyzing the output of bulk preparement department, it is seen that bulk prepared for the two departments are the same which brings an opportunity for the analysis.

Firstly, time sheets are prepared to learn how much of the labor time is used to perform the relevant activities. Workers filled the time sheet and as a result, the activity knowledge of the processes and related percentage times are obtained. The time sheets are edited and necessary corrections are made. While some of the activities are merged, some of them are discarded. After this stage, the wage data is requested from the accounting department and labor cost of the activities are determined.

If the amount of the activities that each product consumes can be learnt, the product costing can be calculated by taking the sum of the costs of the activities consumed by these products. Observations and necessary examinations are done to reach this knowledge and the conversion costs are loaded onto the activities. Cost of rent is loaded according to the space required for each activity and similarly, the power, depreciation and other conversion costs are loaded on the activities according to the activities' consumption of the resources. If activity a uses $2 / 5$ and activity b covers $1 / 5$, while activity c covers $2 / 5$ of the department space, then activity $\mathrm{a}$ is given $2 / 5, \mathrm{~b}$ is given $1 / 5$ and $\mathrm{c}$ is given $2 / 5$ of rent. All the conversion costs are distributed by using the same logic.

The activities performed during classical casting are: molding, drilling assembly holes, rework, equipment clean-up, drilling function holes and carrying. The activity driver for molding is the processing time, for drilling assembly holes is the number of holes, for rework is the number of outputs, for equipment cleanup is the total processing time, for drilling function holes is the total number of function holes and for carrying are the number of processed units in this department, unit area the product allocates on the carrier and the total area of carried goods.

The activities performed during pressured casting are: molding, drilling lateral holes, setup, cutting excess materials from the products, general rework, carrying WIP, drilling assembly holes, ring preparation, drilling some subcomponents washbasins, washbasin drilling, rework of back of the products, Xpatch control, bringing the WIP, helping to other departments, filling forms, mold check-up, WIP control, equipment and personnel control, drilling water holes. The activity driver for molding is the number molds used, for drilling lateral holes is the number of output, for setup are the incoming units, setup hour, setup for other products, setup for basins, setup for other products, for cutting excess materials from the products is the incoming units, for general rework is also the incoming units, for carrying WIP is the number of output, 
for drilling assembly hole and for ring preparation is the number of output, for drilling some sub-components washbasins is the number of subcomponents, for washbasin drilling is the number of washbasins, rework of back of the products and X-patch control is the number of output, for bringing the WIP is the incoming WIP, for helping to other departments is the number of reservoirs, for filling forms, mold check-up, WIP control, equipment and personnel control, drilling water holes is the incoming units.

The activities performed during glazing are maintenance, glazing with hand, WIP transfer, rework, closet shaking, planning, routine controls and prism data entry. The activity driver for maintenance is the number of reworked parts, for glazing with hand is the weight of parts to be glazed, for WIP transfer and rework is the number of reworked parts, for closet shaking is the number of closets, for planning, routine controls and prism data entry is the planned units.

The activities performed in the tunnel oven department are tunnel oven activity, transfer to oven, transfer from oven, heat control, oven security control, planning, routine controls, prism data entry, taking records, second heat treatment activity, WIP feeding to the oven, rework of heat processed units and special treatment. The activity driver for tunnel oven activity, transfer to oven, transfer from oven, heat control and oven security control is the total area covered by the heated units, for planning, routine controls, prism data entry and taking records is the total sum of outputs, for second heat treatment activity and WIP feeding to the oven is total area covered by all units, for rework of heat processed units and special treatment is the total area covered by outputs.

The activities performed in the packaging department are packaging, shrinking, clean-up, organizing the finished products, maligning, and product function control and transferring the outputs. The activity driver for packaging, and shrinking is the packaged volume, for clean-up is the total number of units cleaned, for organizing the finished products, maligning, product function control and transferring the outputs is the total number of outputs.

After finding the product costs of the firm, the costs obtained by process costing methodology and the ABC results of the product costs are compared. From the results, it is seen that there are significant differences between some of the product costs obtained by the two methods.

\section{Conclusions}

ABC utilizes the activity concept and by using the activities, ABC can successfully link the product costs to production knowledge. How a product is produced, how much time is needed to perform an activity and finally how much money is absorbed by performing this task are answered by the help of ABC studies.

An S-Curve will exist after the comparison of the traditional and ABC costs [8]. The following notation is used for the comparison of the two product cost values. \% Bias of $\mathrm{ABC}$ from traditional costing is found for each product.

$\%$ bias $=(\mathrm{ABC}$ cost $/$ traditional cost $) * 100$.

Product costs under ABC and traditional costing views can be used to design a table (Table 1) which illustrates \% bias of $\mathrm{ABC}$ and traditional costs. 
Table 1. Comparison of the two product cost values

\begin{tabular}{|c|c|c|c|}
\hline Products & $\%$ Bias & Products & $\%$ Bias \\
\hline Product 70 & 10.415 & Product 28 & \begin{tabular}{|l|}
102.938 \\
\end{tabular} \\
\hline Product 23 & 54.796 & Product 56 & 103.417 \\
\hline Product 64 & 60.439 & Product 48 & 105.092 \\
\hline Product 12 & 65.043 & Product 4 & 108.269 \\
\hline Product 59 & 69.485 & Product 63 & 108.905 \\
\hline Product 47 & 71.071 & Product 53 & 109.488 \\
\hline Product 62 & 75.279 & Product 46 & 112.454 \\
\hline Product 31 & 77.736 & Product 11 & 114.009 \\
\hline Product 1 & 78.621 & Product 54 & 117.228 \\
\hline Product 37 & 78.953 & Product 50 & 124.241 \\
\hline Product 3 & 79.965 & Product 8 & 124.84 \\
\hline Product 22 & 80.527 & Product 6 & 133.134 \\
\hline Product 30 & 80.731 & Product 44 & 134.926 \\
\hline Product 42 & 83.265 & Product 7 & 162.302 \\
\hline Product 19 & 84.533 & Product 14 & 164.557 \\
\hline Product 58 & 89.282 & Product 29 & 169.465 \\
\hline Product 36 & 89.531 & Product 5 & 219.781 \\
\hline Product 20 & 96.504 & Product 15 & 317.231 \\
\hline Product 26 & 96.688 & Product 39 & 584.387 \\
\hline Product 24 & 100.077 & Product 32 & 1198.251 \\
\hline Product 55 & 100.521 & & \\
\hline
\end{tabular}

Note that the table includes only the products that are sold. Products that are not sold but left as semi products are not involved.

The results show 3 significant regions:

1. Products undercosted by traditional costing:

The costs of these products are higher than the "process-costing" and when plotted are greater than the value 100 at y axis. Before the ABC study was implemented, firm was not aware of this hidden loss of money for each of these products. By the help of the ABC study, people noticed this "hidden loss" and pricing decisions are examined.

2. Products overcosted by the traditional methods:

These products are the ones which have smaller values than the value 100 of y-axis. By the help of the ABC, firm realized that, the costs of these products are lower than the costs obtained by process costing. A "hidden profit zone" occurs for these products. Without any intention, a hidden benefit is gained from these products by traditional costing. But noticing the real $\mathrm{ABC}$ costs of these products, the firm can re-price these outputs and can gain a competitive advantage.

3. Products which are costed almost the same:

These are the products whose costs result nearly the same by using the two methods. A narrow band of 20 percentage (\%80-\%120) can be accepted for this region. 


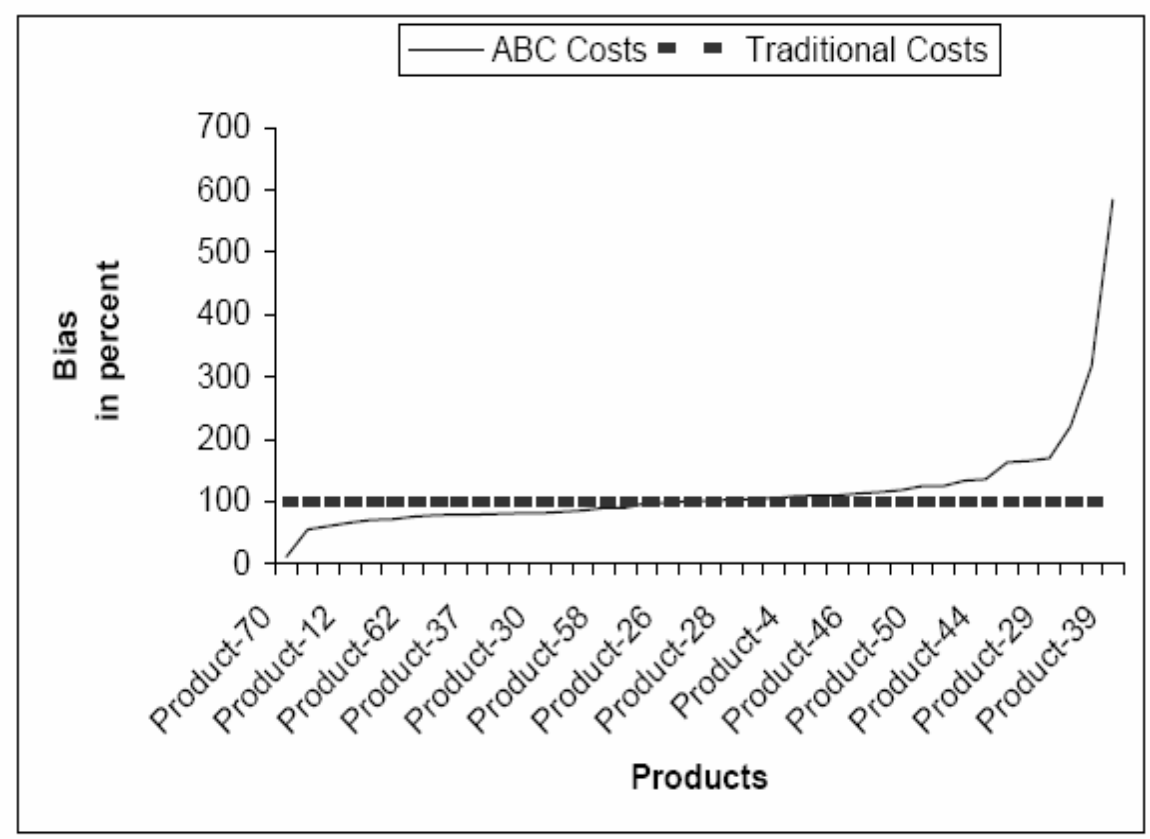

Fig. 1. S-Curve

From the ABC analysis, it is seen that while some of the products are undercosted, and overcosted, some of them give nearly the same results.

In the analysis, the cost calculations of the bulk preparement department are performed using traditional costing method. When the outputs of the processes are identical or nearly identical, then ABC must be avoided to implement. Because $\mathrm{ABC}$ consumes lots of time, data and efforts, implementation of it has also a cost. For identical outputs, both $\mathrm{ABC}$ and traditional give the same results, so it is not logical to implement ABC.

By the help of this analysis, product-pricing decisions gain importance. Pricing decisions can be done under the scope of these hidden losses and profits. According to the ABC results, the company will probably increase or decrease some of its product costs to gain more competitive advantage.

The costing process of the company highlighted some weaknesses of the information system, too. These problems are also expected to be fixed in the future.

As it is seen in this application, $\mathrm{ABC}$ is capable of monitoring the hidden losses and profits of the traditional costing methods. The existence of S-Curve shows which ones of the products are under or overcosted. As a further work, in the company, performance analysis are expected to be done and especially Balanced Score Card (BSC) implementations can be performed. The existence of the $\mathrm{ABC}$ database is an advantage for $\mathrm{BSC}$ applications since its financial phase recommends an ABC implementation. Kaizen applications and BSC can give the firm great advantages in the short and long run under the scope of ABC. 
The studies in literature promote that $\mathrm{ABC}$ is a promising method to support pricing, product mix, and make or buy decisions in manufacturing companies. $\mathrm{ABC}$ is a fruitful area for researchers and has high potential for novel applications such as the hybridization of $\mathrm{ABC}$ with meta-heuristics methods as Artificial Neural Networks, Genetic Algorithms, and Simulated Annealing.

\section{References}

1. Ozbayrak, M., Akgun, M., and Turker, A.K.: Activity-based cost estimation in a push/pull advanced manufacturing system. Int. J. of Production Economics, vol. 87 (2004) 49-65.

2. Cooper, R. and Kaplan, R. S.: How cost accounting distorts product costs. Management Accounting, vol.69 (1988) 20-27.

3. Kim, G., Park, C. S., and Kaiser, M. J.: Pricing investment and production activities for an advanced manufacturing system, Engineering Economist, vol. 42, no. 4 (1997) 303-324.

4. Gunasekaran, A., and Sarhadi, M.: Implementation of activity-based costing in manufacturing. Int. J. of Production Economics, vol.56-57 (1998) 231-242.

5. Ben-Arieh, D. and Qian L.: Activity-based cost management for design and development stage. Int. J. of Production Economics, vol.83 (2003) 169-183.

6. Lewis, R. J.: Activity-based models for cost management systems. Quorum Books, West-port, CT (1995).

7. Koker, U.: Activity-based costing: Implementation in a sanitaryware company. M.Sc. Thesis, Department of Industrial Engineering, University of Dokuz Eylul (2003).

8. Cokins, G.: Activity-based cost management making it works. McGraw-Hill. Inc. (1997). 